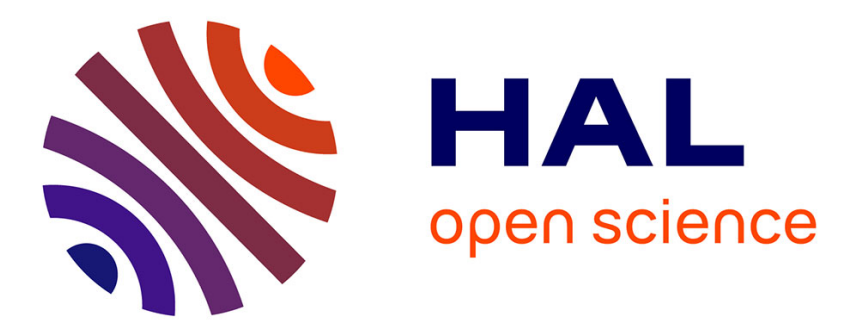

\title{
Topological gradient for fourth order PDE and application to the detection of fine structures in $2 \mathrm{D}$ images
}

\author{
Gilles Aubert, Audric Drogoul
}

\section{- To cite this version:}

Gilles Aubert, Audric Drogoul. Topological gradient for fourth order PDE and application to the detection of fine structures in 2D images. Comptes rendus de l'Académie des sciences. Série I, Mathématique, 2014, http://www.sciencedirect.com/science/article/pii/S1631073X14001411. 10.1016/j.crma.2014.06.005 . hal-01018207

\section{HAL Id: hal-01018207 https://hal.science/hal-01018207}

Submitted on 4 Jul 2014

HAL is a multi-disciplinary open access archive for the deposit and dissemination of scientific research documents, whether they are published or not. The documents may come from teaching and research institutions in France or abroad, or from public or private research centers.
L'archive ouverte pluridisciplinaire HAL, est destinée au dépôt et à la diffusion de documents scientifiques de niveau recherche, publiés ou non, émanant des établissements d'enseignement et de recherche français ou étrangers, des laboratoires publics ou privés. 


\title{
Topological gradient for fourth order PDE and application to the detection of fine structures in 2D images
}

\author{
Gilles Aubert ${ }^{\mathrm{a}}$, Audric Drogoul ${ }^{\mathrm{a}}$

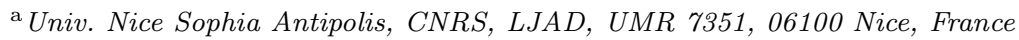 \\ Received $* * * * * ;$ accepted after revision +++++ \\ Presented by
}

\begin{abstract}
In this paper we describe a new approach for the detection of fine structures in an image. This approach is based on the computation of the topological gradient associated to a cost function defined from a regularization of the data (possibly noisy). We get this approximation by solving a fourth order PDE. The study of the topological sensitivity is made both in the cases of a circular inclusion and a crack. We illustrate our approach by giving two experimental results. To cite this article: A. Name1, A. Name2, C. R. Acad. Sci. Paris, Ser. I 340 (2005).
\end{abstract}

\section{Résumé}

Gradient topologique pour des EDP du quatrième ordre et application à la détection de structures fines dans des images 2D. Dans cette note on décrit une nouvelle approche pour la détection de structures fines dans une image. Cette approche est basée sur le calcul du gradient topologique associé à une fonction coût définie à partir des dérivées secondes d'une régularisation des données (éventuellement bruitées). Cette régularisation est obtenue via la résolution d'une EDP du quatrième ordre. L'étude de la sensibilité topologique est faite dans les cas d'une inclusion circulaire et d'un crack. Nous illustrons notre approche en donnant deux résultats expérimentaux. Pour citer cet article: A. Name1, A. Name2, C. R. Acad. Sci. Paris, Ser. I 340 (2005).

\section{Version française abrégée}

Dans cette note on propose un nouveau modèle pour la détection de structures fines (points et filaments) dans une image définie sur un domaine $\Omega \subset \mathbb{R}^{2}$. Notre modèle est basé sur l'étude de la sensibilité topologique d'une fonction coût $j(\Omega)=J\left(\Omega, u_{\Omega}\right)$ où $u_{\Omega}$ est la solution d'une EDP du quatrième ordre. Nous étudions cette sensibilité lorsqu'on perturbe $\Omega$ en lui enlevant des objets $\omega_{\epsilon}$ de taille $\epsilon$. Les exemples

Email addresses: gaubert@unice.fr (Gilles Aubert), drogoula@unice.fr (Audric Drogoul). 
les plus simples adaptés à l'étude de structures fines sont $\omega_{\epsilon}=B\left(x_{0}, \epsilon\right)$ la boule de centre $x_{0}$ et de rayon $\epsilon$ et $\omega_{\epsilon}=x_{0}+\epsilon \sigma(n)$ où $\sigma(n)$ est un segment de droite de normale $n$. Nous montrons pour ces exemples que $j\left(\Omega_{\epsilon}\right)$ admet le développement asymptotique $(1)$ où $\mathcal{I}\left(x_{0}\right)$ est, par définition, le gradient topologique au point $x_{0}$. Par conséquent si on veut minimiser $j\left(\Omega_{\epsilon}\right)$ il est souhaitable d'insérer des petites boules ou des cracks aux points $x_{0}$ où $\mathcal{I}\left(x_{0}\right)$ est "le plus négatif" possible. D'un point de vue de l'analyse d'images ces petites structures correspondent aux structures fines qu'on veut détecter. La question est : quelles fonction coût et EDP doit on utiliser pour détecter de telles structures? Si pour la détection de contours d'objets dans une image il est classique d'utiliser des opérateurs construits à partir du gradient spatial, ce choix est complètement inopérant pour la détection de structures fines : le gradient "ne voit pas" ces structures. Pour détecter ce type de structures il est connu ([10],[7]) qu'il faut utiliser des opérateurs différentiels d'ordre 2. Nous avons choisi pour cela la fonction coût définie en (2) liée à la modélisation de l'équilibre d'une plaque mince soumise à des forces extérieures. Le calcul très technique du gradient topologique revient à estimer la différence $J_{\epsilon}\left(u_{\epsilon}\right)-J_{0}\left(u_{0}\right)$ où $J_{\epsilon}(u)=J_{\Omega_{\epsilon}}(u)$. $u_{\epsilon}$ est l'unique solution du problème variationnel $a_{\epsilon}\left(u_{\epsilon}, v\right)=l_{\epsilon}(v)$, pour tout $v$ dans $H\left(\Omega_{\epsilon}\right)=\left\{u \in L^{2}\left(\Omega_{\epsilon}\right), \nabla^{2} u \in L^{2}\left(\Omega_{\epsilon}\right)\right\}$ où $a_{\epsilon}(u, v)$ et $l_{\epsilon}(v)$ sont définis respectivement par (3) et (4). L' expression du gradient topologique est donnée en (16), (15) pour le cas du crack et (17) pour le cas d'une inclusion circulaire. On conclut cette note en illustrant l'approche par deux résultats expérimentaux.

\section{Introduction}

In medical, biological or satellite imaging the detection of fine structures (filaments, particles ...) is an important task. In this note we show how it is possible to solve this problem by using topological optimization tools. Initially used for cracks detection [8] the notion of topological gradient has been recently applied in imaging problems such as the restoration, the segmentation or the classification of images ([4], [3]). Roughly speaking, the topological gradient approach performs as follows : let $\Omega$ be an open bounded set of $\mathbb{R}^{2}$ and $j(\Omega)=J\left(\Omega, u_{\Omega}\right)$ be a cost function where $u_{\Omega}$ is the solution of a given PDE. For small $\epsilon>0$, let (a) $\Omega_{\epsilon}=\Omega \backslash \overline{\left\{x_{0}+\epsilon \omega\right\}}$ or (b) $\Omega_{\epsilon}=\Omega \backslash \overline{\left\{x_{0}+\epsilon \sigma(n)\right\}}$, where $x_{0} \in \Omega, \omega=B(O, 1)$ is the unit ball of $\mathbb{R}^{2}$ and $\sigma(n)$ is a straight segment with normal $\mathrm{n}$ (a crack). The topological sensitivity provides an asymptotic expansion of $j\left(\Omega_{\epsilon}\right)$ when $\epsilon \rightarrow 0$. In many cases it takes the form :

$$
j\left(\Omega_{\epsilon}\right)=j(\Omega)+\epsilon^{2} \mathcal{I}\left(x_{0}\right)+o\left(\epsilon^{2}\right)
$$

$\mathcal{I}\left(x_{0}\right)$ is called the topological gradient at $x_{0}$. Thus if we want to minimize $j\left(\Omega_{\epsilon}\right)$ it would be preferable to insert small balls or cracks at points $x_{0}$ where $\mathcal{I}\left(x_{0}\right)$ is "the most negative". In imaging applications, the main question is the choice of the cost function and the PDE that $u_{\Omega}$ has to verify.

If for edge detection the usual spatial gradient is classicaly used, it is totally inefficient for the detection of points or filaments. It "does not see"these structures. It is known $([10],[7])$ that for the detection of fine structures we need to use algorithms based on second order derivatives. In section 2 we introduce the cost function $j\left(\Omega_{\epsilon}\right)$ and the variational formulation for $u_{\Omega}$. Then in section 3 we give the expression of the associated topological gradient in cases (a) and (b). In section 4, we briefly describe the numerical approximation of the problem and we conclude by giving two experimental results. 


\section{Definition of the cost function and of the variational formulation for the detection of fine structures}

Let $\Omega \subset \mathbb{R}^{2}$ be the image domain and $f \in L^{2}(\Omega)$ the grey levels of a 2-D image for which we want to detect fine structures that we liken to points or straight lines. The simplest choice of the cost function would be $J_{\Omega}(u)=\int_{\Omega}\left|\nabla^{2} u\right|^{2}$ but for eventual other applications, we introduce a more general cost function stemming from the Kirchhoff model in the theory of thin plates $(0 \leq \nu<1$ denotes the Poisson ratio) :

$$
J_{\Omega}(u)=\int_{\Omega}\left((\Delta u)^{2}+2(1-\nu)\left(\left(\frac{\partial^{2} u}{\partial x_{1} \partial x_{2}}\right)^{2}-\frac{\partial^{2} u}{\partial x_{1}^{2}} \frac{\partial^{2} u}{\partial x_{2}^{2}}\right)\right) d x
$$

We remark that for $\nu=0$ we retrieve the square of the norm of the Hessian matrix. In the sequel $\Omega_{\epsilon}$ is defined as in (a) or (b); for $\epsilon=0, \Omega_{0}=\Omega$. We denote $u_{\epsilon}=u_{\Omega_{\epsilon}}$. Now, for the definition of $u_{\epsilon}$, in order to study the variations of $J_{\Omega_{\epsilon}}\left(u_{\epsilon}\right)$ it is coherent and natural to search for $u_{\epsilon}=\underset{u \in H^{2}\left(\Omega_{\epsilon}\right)}{\operatorname{argmin}}\left(J_{\Omega_{\epsilon}}(u)+\|f-u\|_{L^{2}\left(\Omega_{\epsilon}\right)}^{2}\right)$ or equivalently as the solution of the variationnal problem :

$$
\begin{gathered}
\text { find } u_{\epsilon} \in H^{2}\left(\Omega_{\epsilon}\right) \text { such that } a_{\epsilon}\left(u_{\epsilon}, v\right)=l_{\epsilon}(v), \forall v \in H^{2}\left(\Omega_{\epsilon}\right) \\
a_{\epsilon}(u, v)=\int_{\Omega_{\epsilon}} \Delta u \Delta v+(1-\nu)\left(2 \frac{\partial^{2} u}{\partial x_{1} \partial x_{2}} \frac{\partial^{2} v}{\partial x_{1} \partial x_{2}}-\frac{\partial^{2} u}{\partial x_{1}^{2}} \frac{\partial^{2} v}{\partial x_{2}^{2}}-\frac{\partial^{2} u}{\partial x_{2}^{2}} \frac{\partial^{2} v}{\partial x_{1}^{2}}\right)+u v \\
l_{\epsilon}(v)=\int_{\Omega_{\epsilon}} f v d x
\end{gathered}
$$

Thanks Lax-Milgram Lemma, $u_{\epsilon}$ is unique in $H^{2}\left(\Omega_{\epsilon}\right)$. Moreover $u_{\epsilon}$ satisfies the Euler equation

$$
\left\{\begin{array}{l}
\Delta^{2} u_{\epsilon}+u_{\epsilon}=f, \text { in } \Omega_{\epsilon} \\
B_{1}\left(u_{\epsilon}\right)=0, B_{2}\left(u_{\epsilon}\right)=0 \text { on } \partial \Omega_{\epsilon}
\end{array}\right.
$$

with

$$
\left\{\begin{array}{l}
B_{1}(u)=\partial_{n}(\Delta u)-(1-\nu) \partial_{\sigma}\left(n_{1} n_{2}\left(\frac{\partial^{2} u}{\partial x_{1}^{2}}-\frac{\partial^{2} u}{\partial x_{2}^{2}}\right)-\left(n_{1}^{2}-n_{2}^{2}\right) \frac{\partial^{2} u}{\partial x_{1} \partial x_{2}}\right) \\
B_{2}(u)=\nu \Delta u+(1-\nu)\left(n_{1}^{2} \frac{\partial^{2} u}{\partial x_{1}^{2}}+n_{2}^{2} \frac{\partial^{2} u}{\partial x_{2}^{2}}+2 n_{1} n_{2} \frac{\partial^{2} u}{\partial x_{1} \partial x_{2}}\right)
\end{array}\right.
$$

where $n=\left(n_{1}, n_{2}\right)$ is the outside normal to $\partial \Omega_{\epsilon}$ and $\sigma=\left(\sigma_{1}, \sigma_{2}\right)$ is the tangent vector with $|n|=|\sigma|=1$. Remark 1 The study of topological sensitivity for fourth order operators is not new. In [1], the authors in a different context, compute the topological gradient for the Kirchhoff plate bending problem in case (a) of a circular inclusion. Our model is simpler and we are able to give explicit expressions of the topological gradients both in the cases of circular inclusions and of cracks.

\section{Computation of the topological gradient associated to $J_{\Omega_{\epsilon}}\left(u_{\epsilon}\right)$}

We denote $J_{\epsilon}(u)=J_{\Omega_{\epsilon}}(u)$ and to shorten the presentation we only give the main idea in case (b) : $\Omega_{\epsilon}=\Omega \backslash \overline{\left\{x_{0}+\epsilon \sigma\right\}}$, with $x_{0}=0$ i.e $\Omega_{\epsilon}=\Omega \backslash \overline{\{\epsilon \sigma\}}$ where $\sigma$ is the straight crack $\sigma=\{(s, 0),-1<s<1\}$. We denote $\sigma_{\epsilon}=\epsilon \sigma$. For a detailed version of the calculus we refer the reader to [2]. We have to estimate the difference $J_{\epsilon}\left(u_{\epsilon}\right)-J_{0}\left(u_{0}\right)$. By using equations (5) and (6) for $u_{\epsilon}$ and $u_{0}$, we get

$$
J_{\epsilon}\left(u_{\epsilon}\right)-J_{0}\left(u_{0}\right)=L_{\epsilon}\left(u_{\epsilon}-u_{0}\right)+\mathcal{I}_{\epsilon}
$$


with

$$
L_{\epsilon}(v)=\int_{\Omega_{\epsilon}}\left(f-2 u_{0}\right) v d x \quad \text { and } \quad \mathcal{I}_{\epsilon}=-\int_{\Omega_{\epsilon}}\left(u_{\epsilon}-u_{0}\right)^{2} d x
$$

The first key point is to introduce $v_{\epsilon} \in H^{2}\left(\Omega_{\epsilon}\right)$ as the unique solution of the dual problem (see [9] and [8])

$$
a_{\epsilon}\left(u, v_{\epsilon}\right)=-L_{\epsilon}(u), \forall u \in H^{2}\left(\Omega_{\epsilon}\right)
$$

By extending $\sigma$ to a closed curve, by using integration by parts and the equation verified by $u_{0}$, we obtain

$$
J_{\epsilon}\left(u_{\epsilon}\right)-J_{0}\left(u_{0}\right)=\int_{\sigma_{\epsilon}}\left(B_{1}\left(u_{0}\right)-\alpha \partial_{n} u_{0}\right)\left[v_{\epsilon}\right]-B_{2}\left(u_{0}\right)\left[\partial_{n} v_{\epsilon}\right]+\mathcal{I}_{\epsilon}
$$

where $\left[v_{\epsilon}\right]$ and $\left[\partial_{n} v_{\epsilon}\right]$ denote respectively the jump of $v_{\epsilon}$ and $\partial_{n} v_{\epsilon}$ across $\sigma_{\epsilon}$. Then we set $w_{\epsilon}=v_{\epsilon}-v_{0}$ where $v_{0}$ is the solution of (8) with $\epsilon=0\left(\Omega_{0}=\Omega\right)$, thus :

$$
J_{\epsilon}\left(u_{\epsilon}\right)-J_{0}\left(u_{0}\right)=\int_{\sigma_{\epsilon}}\left(B_{1}\left(u_{0}\right)-\alpha \partial_{n} u_{0}\right)\left[w_{\epsilon}\right]-B_{2}\left(u_{0}\right)\left[\partial_{n} w_{\epsilon}\right]+\mathcal{I}_{\epsilon}=I_{A}-I_{B}+\mathcal{I}_{\epsilon}
$$

with

$$
I_{A}=\int_{\sigma_{\epsilon}}\left(B_{1}\left(u_{0}\right)-\alpha \partial_{n} u_{0}\right)\left[w_{\epsilon}\right], I_{B}=\int_{\sigma_{\epsilon}} B_{2}\left(u_{0}\right)\left[\partial_{n} w_{\epsilon}\right]
$$

The estimation of the two terms of (11) needs to approximate $w_{\epsilon}$. It is classical (see [8]) to approximate $w_{\epsilon}$ by the solution of the exterior problem

$$
\left\{\begin{array}{l}
\Delta^{2} P=0, \text { in } \mathbb{R}^{2} \backslash \bar{\sigma} \\
B_{1}(P)=g_{1}, B_{2}(P)=g_{2} \text { on } \sigma
\end{array}\right.
$$

where $g_{1}$ end $g_{2}$ are known functions defined from second derivatives of $v_{0}$ at point 0 . The solution of (12) is the sum of triple and quadruple layer potentials (see [2] for more details). We can show that $w_{\epsilon}=v_{\epsilon}-v_{0}$ can be written as $w_{\epsilon}(x)=\epsilon^{2} P\left(\frac{x}{\epsilon}\right)+e_{\epsilon}$ with $\left\|e_{\epsilon}\right\|_{2, \Omega_{\epsilon}}=0\left(-\epsilon^{2} \log (\epsilon)\right)$ and then the three terms in (10) have the following expansion :

$$
I_{A}=o\left(\epsilon^{2}\right), I_{B}=\epsilon^{2} \gamma \int_{\sigma} \lambda_{2}(y) d \sigma_{y}+o\left(\epsilon^{2}\right), \mathcal{I}_{\epsilon}=o\left(\epsilon^{2}\right)
$$

with $\gamma=\frac{\partial^{2} u_{0}}{\partial x_{2}^{2}}(0)+\nu \frac{\partial^{2} u_{0}}{\partial x_{1}^{2}}(0)$ and $\left.\lambda_{2}(s)=\frac{-4 \beta}{(1-\nu)(3+\nu)} \sqrt{1-s^{2}}, \forall s \in\right]-1,1\left[\right.$, where $\beta=\frac{\partial^{2} v_{0}}{\partial x_{2}^{2}}(0)+\nu \frac{\partial^{2} v_{0}}{\partial x_{1}^{2}}(0)$. Gathering estimates (10) and (13) we get the expression of the topological gradient for the case $\Omega_{\epsilon}=\Omega \backslash \sigma_{\epsilon}$ and $x_{0}=0$ :

$$
\mathcal{I}(0)=-\frac{2 \pi}{(1-\nu)(3+\nu)}\left(\frac{\partial^{2} u_{0}}{\partial x_{2}^{2}}(0)+\nu \frac{\partial^{2} u_{0}}{\partial x_{1}^{2}}(0)\right)\left(\frac{\partial^{2} v_{0}}{\partial x_{2}^{2}}(0)+\nu \frac{\partial^{2} v_{0}}{\partial x_{1}^{2}}(0)\right)
$$

Remark 2 Thanks to a basis change, the topological gradient for a straight crack centered at $x_{0} \in \Omega$ and of normal $n$ is given by

$$
\mathcal{I}\left(x_{0}, n\right)=\frac{-2 \pi}{(1-\nu)(3+\nu)}\left(\nabla^{2} u_{0}\left(x_{0}\right)(n, n)+\nu \nabla^{2} u_{0}\left(x_{0}\right)(\tau, \tau)\right)\left(\nabla^{2} v_{0}\left(x_{0}\right)(n, n)+\nu \nabla^{2} v_{0}\left(x_{0}\right)(\tau, \tau)\right)
$$

with $\tau$ the tangent vector such as $(\tau, n)$ is an orthonormal basis of $\mathbb{R}^{2}$ and the topological gradient at point $x_{0} \in \Omega$ is defined as :

$$
\mathcal{I}\left(x_{0}\right)=\min _{\|n\|=1} \mathcal{I}\left(x_{0}, n\right)
$$


Remark 3 In the case of the ball : $\Omega_{\epsilon}=\Omega \backslash \overline{x_{0}+\epsilon B(0,1)}$, the computation is identical (see [2] and [1]) :

$$
\begin{aligned}
& \mathcal{I}\left(x_{0}\right)=\pi\left(f\left(x_{0}\right)-u_{0}\left(x_{0}\right)\right)\left(v_{0}\left(x_{0}\right)-u_{0}\left(x_{0}\right)\right)-\frac{\pi(1+\nu)}{1-\nu} \Delta u_{0}\left(x_{0}\right) \Delta v_{0}\left(x_{0}\right) \\
& \quad-\frac{2 \pi(1-\nu)}{3+\nu}\left(\left(\frac{\partial^{2} u_{0}}{\partial x_{1}^{2}}\left(x_{0}\right)-\frac{\partial^{2} u_{0}}{\partial x_{2}^{2}}\left(x_{0}\right)\right)\left(\frac{\partial^{2} v_{0}}{\partial x_{1}^{2}}\left(x_{0}\right)-\frac{\partial^{2} v_{0}}{\partial x_{2}^{2}}\left(x_{0}\right)\right)+4 \frac{\partial^{2} u_{0}}{\partial x_{2} \partial x_{1}}\left(x_{0}\right) \frac{\partial^{2} v_{0}}{\partial x_{2} \partial x_{1}}\left(x_{0}\right)\right)
\end{aligned}
$$

\section{Numerical approximation and experimental results}

The computation of the topological gradient only need to compute the solutions of the two following variational problems :

$$
\begin{aligned}
& a_{0}\left(u_{0}, v\right)=l_{0}(v), \quad \forall v \in H^{2}(\Omega) \\
& a_{0}\left(u, v_{0}\right)=-L_{0}(u), \quad \forall u \in H^{2}(\Omega)
\end{aligned}
$$

where $l_{0}$ and $L_{0}$ are respectively defined by (4) and (7) with $\epsilon=0$. To discretize (18), we used Morley finite elements (see [5] and [6]). If $\left(\mathcal{T}_{h}\right)_{h}$ is a regular triangulation of $\Omega$, let $X_{h}$ be the Morley finite elements space associated with $\left(\mathcal{T}_{h}\right)_{h}$. We define on $X_{h}$ the bilinear and linear forms :

$$
\begin{aligned}
a_{0, h}(u, v) & =\sum_{\mathcal{K} \in \mathcal{T}_{h}} \int_{\mathcal{K}} \sum_{i, j=1}^{2} \frac{\partial^{2} u}{\partial x_{i} \partial x_{j}} \frac{\partial^{2} v}{\partial x_{i} \partial x_{j}} d x \\
l_{0, h} & =\sum_{\mathcal{K} \in \mathcal{T}_{h}} \int_{\mathcal{K}} f v d x \\
L_{0, h}(v) & =\sum_{\mathcal{K} \in \mathcal{T}_{h}} \int_{\mathcal{K}}\left(f-2 u_{0, h}\right) v d x
\end{aligned}
$$

We denote respectively by $u_{0, h}$ and $v_{0, h}$ the solution of the problems

$$
\begin{array}{r}
a_{0, h}\left(u_{0, h}, v_{h}\right)=l_{0, h}\left(v_{h}\right), \forall v_{h} \in X_{h} \\
a_{0, h}\left(u_{h}, v_{0, h}\right)=-L_{0, h}\left(u_{h}\right), \forall u_{h} \in X_{h}
\end{array}
$$

Then the discrete topological gradient is computed thanks to formula (16) evaluated at vertices of $\left(\mathcal{T}_{h}\right)_{h}$. We illustrate our approach by giving two experimental results in Figure 1 and Figure 2. To determine the size of the structures to be detected, we add in front of the bilaplacian operator a regularizing parameter $\alpha>0$ to be tuned by the user; for example for structures of size 1 to 6 pixels $\alpha=0.1$ and for structures of size 6 to 17 pixels $\alpha=3$. Note also that our topological gradient (TG) is able to distinguish between fine structures and jumps (edges). In a neighborhood of an edge the TG is not equal to 0 but it is weak. On the other hand in a neighborhood of a fine structure it is big, so with a correct threshold we can easily detect fine structures and eliminate jumps.

\section{References}

[1] S. Amstutz and A.A. Novotny, Topological asymptotic analysis of the Kirchhoff plate bending problem., ESAIM, Control Optim. Calc. Var., vol. 17, 3, 2011, 705-721

[2] G. Aubert and A. Drogoul, A topological gradient based model for the detection of fine structures in 2D images (submitted)

[3] D. Auroux and M. Masmoudi and L. Jaafar Belaid, Image restoration and classification by topological asymptotic expansion, Variational Formulations in Mechanics: Theory and Applications, E. Taroco, E.A. de Souza Neto and A.A. Novotny (Eds), CIMNE, Barcelona, Spain, 2007, 23-42 

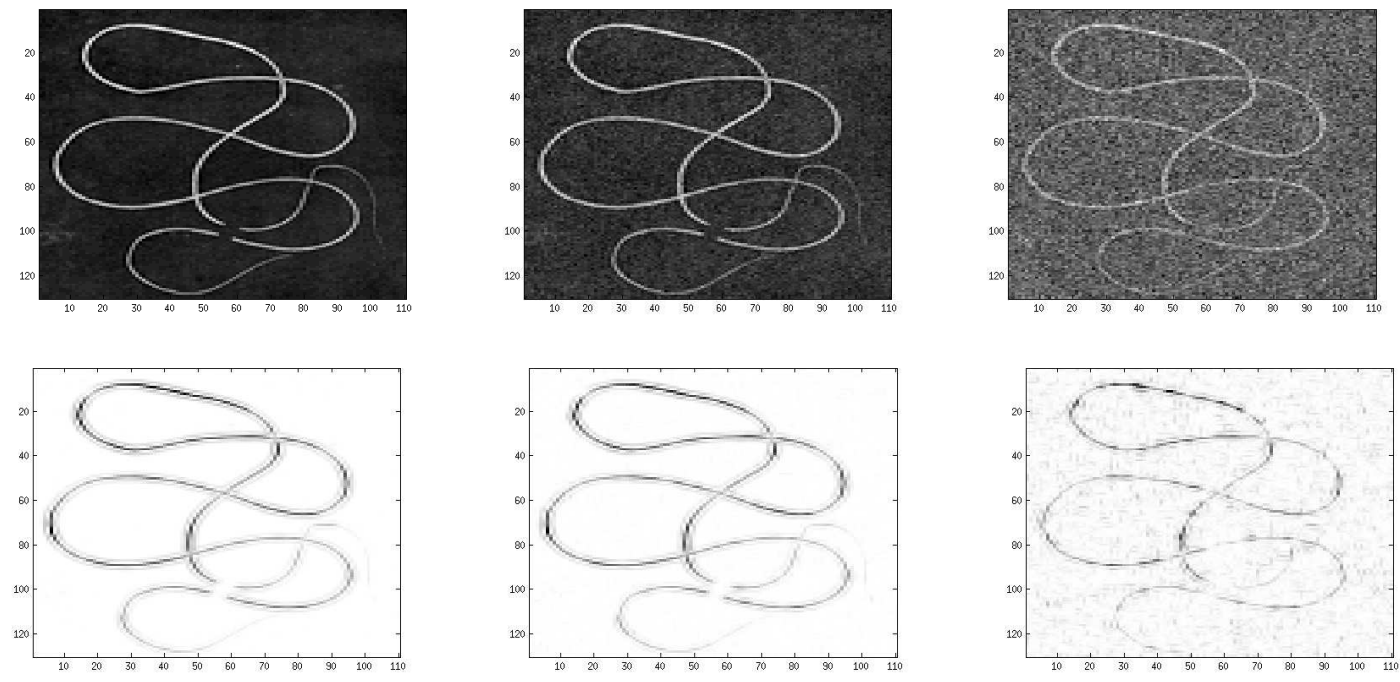

(a)

(b)

(c)

Figure 1. Robustness of the topological gradient with respect to noise on a synthesis image using (16), (a) : Image without noise, (b) : Noisy image with Gaussian noise, PSNR $=26 \mathrm{~dB}$, (c) : Noisy image with Gaussian noise, PSNR $=14 \mathrm{~dB}$, top : Initial image, down : Topological gradient using (16), Robustesse du gradient topologique par rapport au bruit pour une image synthétique en utilisant (16),(a) : Image sans bruit, (b) : Image bruitée par du bruit Gaussien, PSNR=26dB, (c) : Image bruitée par du bruit Gaussien, PSNR $=14 \mathrm{~dB}$, en haut : Image initiale, en bas : Gradient topologique utilisant (16)

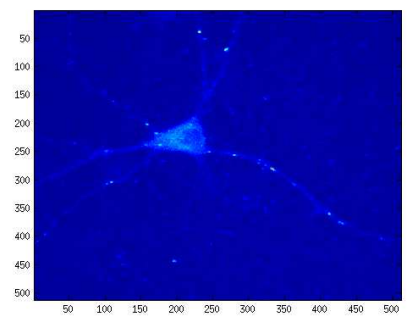

(a) Initial image, Image initiale

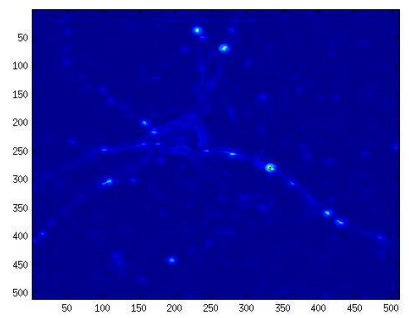

(b) Topological Gradient, Gradient topologique

Figure 2. Topological gradient on a real biological image (rat's neuron) using (16), Gradient topologique sur une image réelle biologique (neurone de rat) utilisant (16)

[4] L. Jaafar Belaid and M. Jaoua and M. Masmoudi and L. Siala, Application of the topological gradient to image restoration and edge detection, Engineering Analysis with Boundary Elements 32, vol. 11, 2008, 891 - 899

[5] S.C Brenner and L.R. Scott, The Mathematical Theory of Finite Element Methods, Springer-Verlag, 2002

[6] W. Ming and J. Xu, Math. Comput., 257, Nonconforming tetrahedral finite elements for fourth order elliptic equations., vol. $76,2007,1-18$

[7] C. Cañero Morales and P. Radeva, Vesselness enhancement diffusion, Pattern Recognition Letters, vol. 24, 16, 2003, 3141-3151

[8] S. Amstutz, I. Horchani, M. Masmoudi, Crack detection by the toplogical gradient method, vol. 34, 1, Control and Cybernetics 2005, 81-101 
[9] J. Sokolowski and A. Zochowski, On the Topological Derivative in Shape Optimization, SIAM J. Control Optim., vol. 37, 4, apr, 1999, 1251-1272

[10] C. Steger, An Unbiased Detector of Curvilinear Structures, IEEE Trans. Pattern Anal. Mach. Intell., vol. 20, 2, 1998, 113-125 